\title{
Guaiaca - a software tool for supporting the use of scientific applications designed for data analysis - part I: execution assistant
}

\section{Guaiaca - uma ferramenta de apoio ao uso de aplicativos científicos destinados a análises de dados - parte I: assistente de execução}

\author{
Gil Carlos Rodrigues Medeiros ${ }^{1 *}$; Willian Silva Barros ${ }^{2}$; Nelson José Laurino Dionello
}

\begin{abstract}
The aim of this work is to develop a software tool that provides a user-friendly graphical interface of generic and configurable design in order to ease the researcher's tasks in data manipulation and analysis. Two primary targets have influenced the design: data preparation for analysis in animal breeding programs and usability increase for those applications that perform important analysis methods, but interact with users only through text files and command lines. The Guaiaca tool was designed as a "utility belt" in the form of two integrated assistants, and it can be combined with multiple analysis applications. This tool offers facilities to: (a) collect, manipulate, and reorganize data; (b) organize, register, and retrieve analyses through descriptors; and (c) prepare and activate analysis processes. Guaiaca's Execution Assistant module is described in this paper, where is also emphasized the parameters to configure, the main data structures to maintain, and the form of the relationship between its generic interface and combined analysis applications. The generic interface has been customized and validated for the peculiarities of two applications, WOMBAT (mixed models) and INTERGEN (Bayesian models). Several data analyses were performed with the interface support to prove its generality and ease of installation, configuration and operation. Data sets from 5,726 quails in a breeding program were used with these applications. Use of the integrated Guaiaca-WOMBAT application is illustrated with an analysis example, prepared and visualized on the Guaiaca tool and executed by WOMBAT. The Beta version of the Guaiaca tool for Windows is available free of charge to the scientific community and can be obtained at http://wp.ufpel.edu.br/gilmedeiros/guaiaca.
\end{abstract}

Key words: Animal breeding. Data analysis. History of analysis. Mixed models. Scientific software. Usability.

\section{Resumo}

O objetivo deste trabalho foi desenvolver uma ferramenta de software com interface gráfica amigável, genérica e configurável, para facilitar pesquisadores na organização e gerenciamento das atividades de manipulação e análises de dados. A concepção foi baseada nas características de dois focos principais: a preparação de dados para análises em pesquisas de melhoramento genético de animais e o incremento da usabilidade para aplicativos que implementam importantes métodos de análises, mas interagem com o usuário via arquivos de texto e linha de comando. A ferramenta Guaiaca foi modelada como um "cinto de utilidades" e desenvolvida na forma de dois assistentes integrados. Pode ser combinada

\footnotetext{
${ }^{1}$ Prof. Dr., Centro de Engenharias, Universidade Federal de Pelotas, UFPel, Pelotas, RS, Brasil. E-mail: gil.medeiros@ufpel.edu. br

2 Prof. Dr., Departamento de Matemática e Estatística, Instituto de Física e Matemática, UFPel, Pelotas, RS, Brasil. E-mail: wsbarros@hotmail.com

${ }^{3}$ Prof. Dr., Departamento de Zootecnia, Faculdade de Agronomia Eliseu Maciel, UFPel, Pelotas, RS, Brasil. E-mail: dionello@ ufpel.edu.br

* Author for correspondence
} 
com múltiplos aplicativos executores de análises. Oferece facilidades para: coleta, manipulação e reorganização de dados; organização, catalogação e recuperação de análises via descritores; ativação de processos de análise. Apresenta-se uma descrição sobre o Assistente de Execução destacando os parâmetros configuráveis, as estruturas de dados mantidas e a forma de relacionamento entre a interface genérica e os aplicativos de análise combinados. A personalização de sua interface foi testada para peculiaridades dos aplicativos WOMBAT (modelos mistos) e INTERGEN (modelos bayesianos). Foram realizadas diversas análises para comprovar sua generalidade e facilidade de instalação, configuração e operação, utilizando dados de 5.726 codornas de um programa de melhoramento. $\mathrm{O}$ uso do conjunto Guaiaca-WOMBAT é ilustrado com exemplo de análise preparada e visualizada no Guaiaca e executada pelo WOMBAT. A versão beta do Guaiaca (para Windows) está disponível de forma gratuita para a comunidade científica e pode ser obtida em http://wp.ufpel.edu.br/gilmedeiros/guaiaca.

Palavras-chave: Análise de dados. Histórico de análises. Melhoramento animal. Modelos mistos. Software científico. Usabilidade.

All experimental research activities assume collecting, handling, and analyzing data. Although performing these tasks manually can be viable in some cases, supporting the dismissal of scientific computing applications in order to perform such tasks effectively and efficiently is unimaginable today. In many cases, it is impossible to perform such tasks without the use of such applications. The availability of adequate scientific applications for every research need is dependent on several factors of economic, technical, political, idiomatic, ethical, innovative, and personnel order, among others. Often, the researcher is motivated by some of these factors to develop the applications needed, with or without the collaboration of qualified partners in specific areas.

In agricultural research, in general, and in the genetic breeding area, in particular, many products have been generated within the scope of this motivation, both to implement techniques related to statistical methods and simulation, and to particularize or specialize these and other techniques (RESENDE, 2007; CRUZ, 2013; FERREIRA, 2013). From these initiatives and the aggregation of advanced computational techniques, the area of bioinformatics has emerged mainly related to the area of molecular biology, and more particularly, to applications in genomic selection and genome-wide selection (LEGARRA et al., 2009; GARRICK; SAATCHI, 2011).

The main concern when developing a scientific application software is undoubtedly the immediate provision of corresponding algorithms to the application object functions. Aspects related to the usability and availability of complementary resources for supporting activities related to the use of these applications are often simplified to the essential minimum, based on the usage needs of the creator/developer and immediate peers. Often this strategy, while necessary in the early stages, can determine the disinterest of potential users for the continued use of a tool after the initial experience. Among the reasons for this disinterest is use difficulty or simply the difficulty of recognizing ease of use, even if the tool can be regarded as being of good quality with regard to its features, or represents an important alternative to recognized resources whose costs are very high. Regardless of this abstraction approach, usability is an important attribute in assessing the software system's quality (MADAN; DUBEY, 2012), and it is strongly associated with ease of use, ergonomics, and degree of user satisfaction. Supporting tasks, such as those involved in data manipulation, are usually referred to in the previous or subsequent use of recognized tools commonly used (electronic spreadsheets and similar), which can also generate costs and require additional knowledge.

The cost of developing operational interfaces for specific application tools can cause the task to often be relegated to a later stage, which could result in being delayed indefinitely. 
For the area of animal genetic breeding, multiple applications are known that define their user interfaces in a simplified manner and depend on the interaction pattern that corresponds to the command line mode in the text window. Among others, the following examples can be cited: DFREML, MTDFREML, WOMBAT, INTERGEN, ASReml, and the BLUPF90 family (MEYER, 1988, 2007; BOLDMAN et al., 1995; CARDOSO, 2008; GILMOUR et al., 2009; MISZTAL et al., 2014). The purpose of these tools is fundamental to the area because they implement models and methods of inference and quantitative data analysis based on the methodology of restricted maximum likelihood (REML) that uses mixed models, thus allowing the simultaneous use of pedigree information and genetic relationship among animals. Their processes are highly iterative and often require the repetitive execution of analysis in order to search for a better approach and/or suitability of the employed model. Dionello et al. (2008) highlighted the use of some of these features (models and applications) in the genetic evaluation of meat quails growth.

Many scientific applications developed according to the profile now characterized have defined their user interaction interfaces based on a standard represented by parameter files in order to define the tasks/analyses to be performed, and report files as plaintext. In some cases, ports are defined for interaction with other applications through specific files with intermediary or conclusive data produced by their processes. This type of application is the primary target of the interface proposed in this work in order to perform survey data analyses.

This document is prepared in order to describe the generic interface of a tool known as Guaiaca that adds better usability characteristics to the scientific applications of data analyses whose models of interaction with the user follow the standard identified above. This is accomplished by integrating such applications with resources (facilities) for data collection and handling, and for organizing, cataloging, and retrieving the performed analyses through a friendly and configurable user interface.

Description and scope. The initial release of Guaiaca was developed in a Delphi ${ }^{\circledR}$ environment for the Windows platform in a prototype form that serves as basis for the subsequent implementation of the multiplatform version. Operation interfaces $\left(\mathrm{GUI}^{4}\right)$ were designed for easy and intuitive interaction through windows and simple features, and they are configurable according to each project and user needs and preferences. The main purpose is to provide the researcher with simple, practical, and easy-to-use features for the tasks of: (a) collecting, organizing, viewing, and manipulating research data; (b) executing data analysis using selected scientific applications; and (c) keeping historical and controlling records about the performed analyses. The second group of tasks corresponds to the preparation and forwarding of the analyses to executing applications. These are generically called target applications in the context of the generic interface. The third group, closely related to the second, includes organization, storage (cataloging), and displaying the parameters and results of these analyses.

Although designed from the perspective of the needs related to research in the animal science area, Guaiaca can be used for any other area whose data are organized in a similar fashion and processed by applications with characteristics similar to those described in the scope of this document. Use of Guaiaca can be characterized in two ways: as a single program that incorporates all its features, or as two independent modules, Data Assistant and Execution Assistant. The first combines the features of collecting and manipulating data, and it was designed to meet the data preparation requirements for processing by any target application. The second combines all the resources related to the generic

\footnotetext{
${ }^{4}$ GUI is an acronym used to represent the term "graphical user interface" - a type of operator interface that allows user interaction with digital devices, intuitively, through graphics (icons and other visual elements, also called widgets), contrasting with the command line interface.
} 
interface for target applications (analysis of statistical data or other types of analyses) and cataloging analyses. The scope of this communication is limited to the Execution Assistant.

Types of target applications. The generallity of the Execution Assistant interface allows a wide range of applications. However, the intended purpose set is directly related to the characteristics of applications that:

a) perform specialized calculations and analysis of data provided via specified files, such as data statistical analysis, simulations, and model assessments or fittings;

b) lack a visual interface operation (GUI);

c) are parameterized through attributes, codes, statements, commands, and options shown in a text file and/or command-line arguments;

d) generate reports in text files and in their own operator console (computer screen).

Configurable parameters. The Guaiaca generic interface for the Execution Assistant module must be set up under the two scopes of its use: the interface itself, characterized by defining user preferences through options available to the user; and the execution of the analyses, characterized by linking the interface to each application target to be used. For each configured binding, identified by a unique name, a new item is inserted into the corresponding menu and a new configuration directory is created in the Guaiaca environment. This menu allows the user to enable the customized interface for the target application, according to the selected setting. In addition to setting the linking to different applications, the user can configure different settings for the same target application. The configuration directory is intended to keep all files for this customization, according to the parameters presented below.

The target applications are installed independently, according to the specific orientation of their origin. For use them combined with the generic interface of the Execution Assistant, the user must set a specific location (directory/folder) for the working area, where its functions will be performed. This area is considered temporary, and will be cleared at the start of each new operation of the target application, i.e., for each analysis run. The user can set the same working area for several or all target applications, provided that there are no limitations imposed by their requirements and the interface form of use. During preparation of the target application execution and after processing, the working area content can be saved (copied) to a permanent location determined by the user. This is done while characterizing and recording the desired analysis, regardless of the state (prepared or performed).

To link the Guaiaca interface to each target application, the following parameters are adopted to be set up through a specific dialog form of the generic interface, and kept in specific folders and files:

a) Target application identification: location (directory/folder) where it was installed; name of the executable file; and name of the help/ manual file;

b) Working area name (directory/folder);

c) Operational information of the target application: the file names that will represent the console input and output (standard input and output); way to inform the parameter file (command line or console input); filters for the recognition of output files; names of the primary output files (shown automatically); code guide (optional file); and options guide (optional file);

d) Demonstration example (optional): data and parameter files for the target application.

Technical details and built-in functions. In addition to the interface customization feature for a target application (as described), the Execution Assistant incorporates two other function groups: the support functions for using the target application, 
and the necessary functions for the maintenance of a historical catalog of performed analyses.

The support functions for using the target application are a group of facilities that: (a) display the input and output files; (b) prepare or visualize the parameter files (also known as programs or scripts); and (c) choose and display the run options (arguments). In order to use the last two facilities (b and c) to their fullest, it is necessary to create files that represent the Code and Options Guides according to the researcher's interest and following the interface documentation guidelines. This can be done by the user or IT support personnel from the target application resources documentation during installation of the applications set. Alternatively, a recommended standard for these files can be prepared in advance and distributed as part of this Execution Assistant, or included in the package distributed by the suppliers or maintainers of each target application. In order to display the target application's input and output files (data, parameters, and reports), a strategy similar to that employed by SAS, a traditional commercial software of management and advanced data analysis, was adopted (DELWICHE; SLAUGHTER, 2012; SAS INSTITUTE INC., 2010). The user has at his or her disposal, accessible with a few clicks via indicators (tabs, buttons, or menus), integrated windows with any important files for the assessment of each designed or performed analysis.

In the context of Guaiaca, each analysis is represented by an Analysis Descriptor whose goal is to maintain a characterization of the task, indicating the resources involved and information concerning the results obtained. Descriptors can be collected into a List of Analyses, i.e., a history catalog of the analyses performed. This catalog is maintained by a group of functions that facilitate the organization and tracking of input data and results processed by the target applications linked to the interface.
This feature can also be used independently of the target application. It is possible to organize and identify each designed analysis, gather and store the associated files, and keep additional information on the task execution, such as date and time of run, application used to process analysis, and supplementary notes of the analyst user. The defined functions allow the user to scroll through the list of cataloged analyses, create new analyses, select and view descriptors and/or previous analysis files, complement or rerun analyses, save files of the analysis (data and results) in the managed environment. It is recommended that this catalog be maintained in a folder called Projects built into the Guaiaca installation environment.

The relationship conception between the Execution Assistant and target applications is based on the coexistence of two independent processes in the computer operating system: the Guaiaca process and the process related to the linked target application. All target application operations are channeled to a common working area managed by the Assistant that prepares and feeds the working area with the files needed to process an analysis by the target application. The Assistant subsequently redirects the results obtained for permanent storage according to the researcher's specifications listed in the analysis descriptor. A demonstrative diagram of this relationship is shown in Figure 1A. In this diagram, are highlighted the main organizational elements of the interface with a focus on an analysis, such as the input files folder, analysis folder, processes and their common working area, the environment for configuration and maintenance of the list of cataloged analyses, and alternative data sources for characterizing an analysis. The characterization of a folder input is differentiated from the analysis folder because a given data set can be used in different analyses. This avoids multiple instances of the same data. 
Figure 1. Two approaches for the integration between Guaiaca and analysis applications: (A) relationship diagram between the Execution Assistant and a Target Application and associated structures, (B) hierarchical file structure of the complete installation with association of two target applications from a chosen location.

(A)

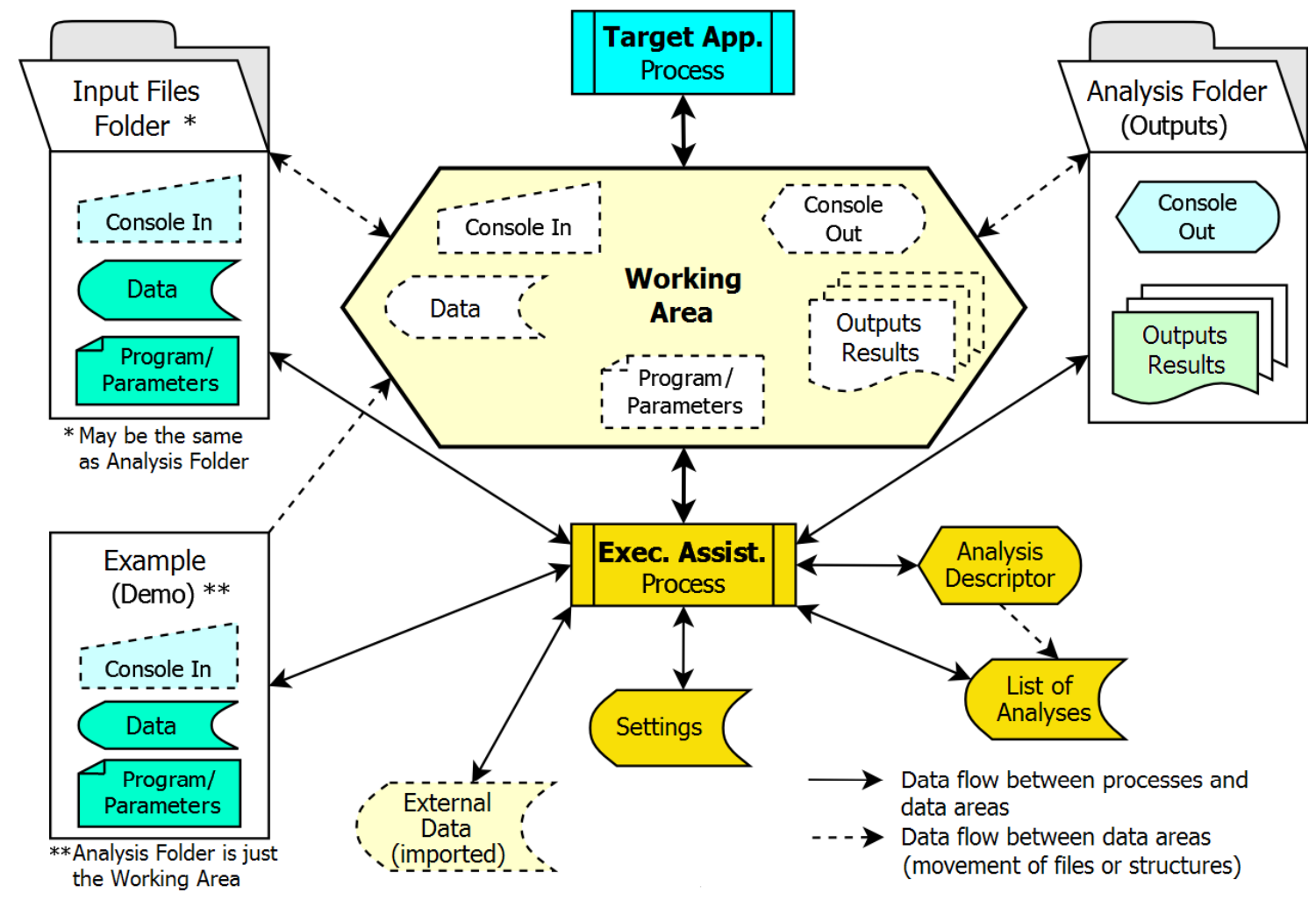

(B)

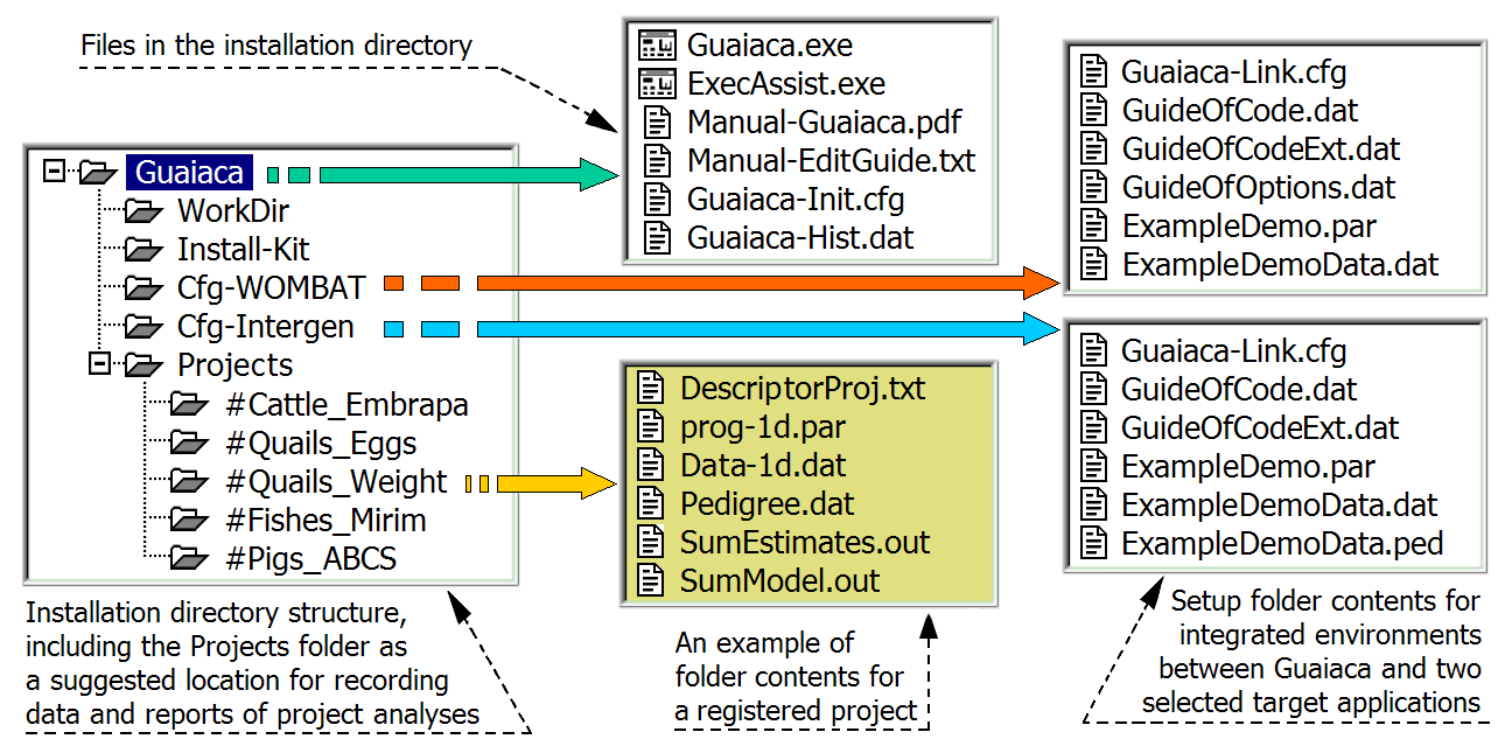


User interface. All interactions between Guaiaca and the user are performed via an interface modeled on the operating system's windowing environment and based on point-and-click operations. The generic interface of the analysis Execution Assistant consists of a set of windows that represent the following: the main operating environment, descriptor of the current analysis, specification to search cataloged analyses, selection of input data and parameter files, connection setup of the Assistant with the target application in use, configuration of interface options or usage preferences, and presentation of the tool. Help documents (manuals and guidelines) are shown in windows also activated by the tool. This action may depend on the standard complementary application presence, such as a PDF reader or another paradigm adopted for the target application manual in use. The presentation of the main window is based on a class of dynamically activated components, which are selected through choices in the interface usage preferences or actions during operation. The main components in this class are: list of cataloged analyses; data file, reports, and operating console viewers; parameter file editor; and code guide and run options guide for the target application. The generic interface main window layout is illustrated in Figure 2A through an instantiated image of the tool configured for use in conjunction with the WOMBAT application. In this instance, the window has its components loaded with the files that correspond to a cataloged analysis called "g1a9-uni28d". Its main visible components are identified by pointers.

Configured applications. Guaiaca was configured and tested to establish, initially, two integrated environments, combining the Execution Assistant and two target applications for statistical analysis that estimate the (co)variance components and consequent genetic parameters. For these environments, were chosen the WOMBAT and INTERGEN applications that concern, respectively, the adjustment of mixed linear models using the REML methodology (MEYER, 2007) and implementation of Bayesian hierarchical models using Monte Carlo Markov Chain methods (CARDOSO, 2008).

Both chosen target applications and Guaiaca were easily installed simply by copying their programs and files to the chosen private directories/ folders. The following structures were established for each application:

a) WOMBAT - the directory. IWOMBAT that contains three items: the executable file wombat. exe, user manual file WombatManual.pdf, and folder Examples with the content defined according to the manual's recommendations (MEYER, 2014), downloaded from http://didgeridoo.une.edu.au/km/ wombat.php;

b) INTERGEN - the directory .IINTERGEN that contains three items: the executable file intergen1.2.exe, user manual file Manual Intergen v1-2.pdf, and folder Examples with the content defined according to the recommendations in the application manual (CARDOSO, 2008), downloaded from http://www.cppsul.embrapa.br/ estaticos/produtoseservicos/english.php;

c) GUAIACA - the directory .IGUAIACA that maintains the structure and components shown in Figure 1B, i.e., the executable and configuration files and tool documentation, a work folder (WorkDir) where the running target application processing occurs (can be unique or specific to each application), a folder (optional) for maintaining the files that compose the installation kit, a configuration folder for the definition of each integrated environment with the target applications, and a folder for project cataloging (data collections and analysis reports). 
Figure 2. Images of Guaiaca/Execution Assistant windows with an example of use and component highlights of the generic interface: (A) main window, (B) main window clipping during browse the history of analysis for select a cataloged analysis, (C) overlapped clippings of the three attribute groups in the descriptor window for current analysis.

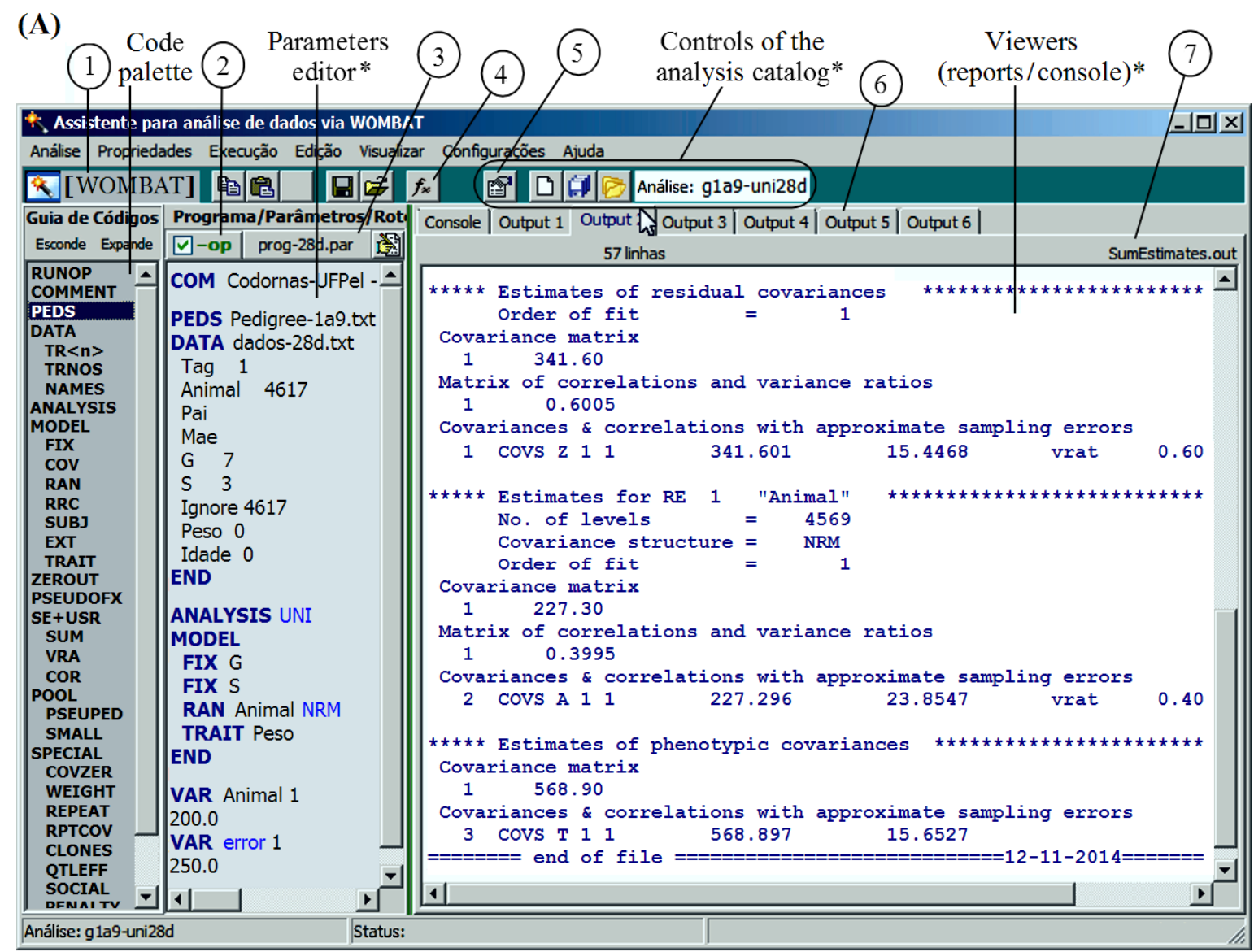

(1) Name of the connected target application. (2) Enabler for run options selector. (3) Parameter file name. (4) Analysis initiator. (5) Analysis descriptor. (6) Indicators of available/enabled outputs. (7) Selected output file name** Example: analysis (g1a9-uni28d) processed by WOMBAT.

(B)

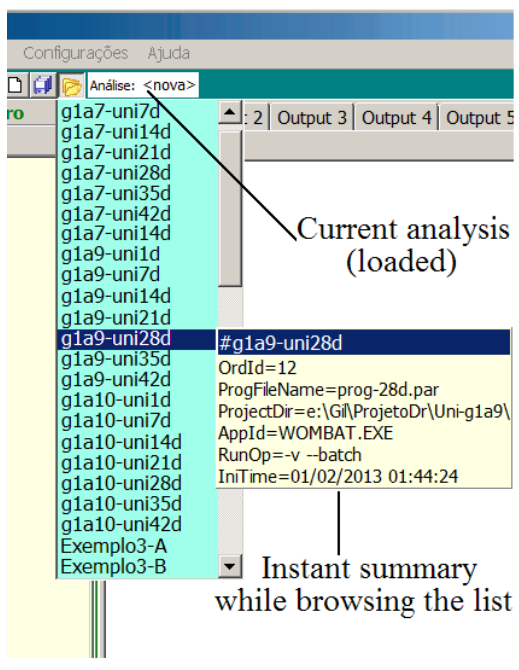

(C)

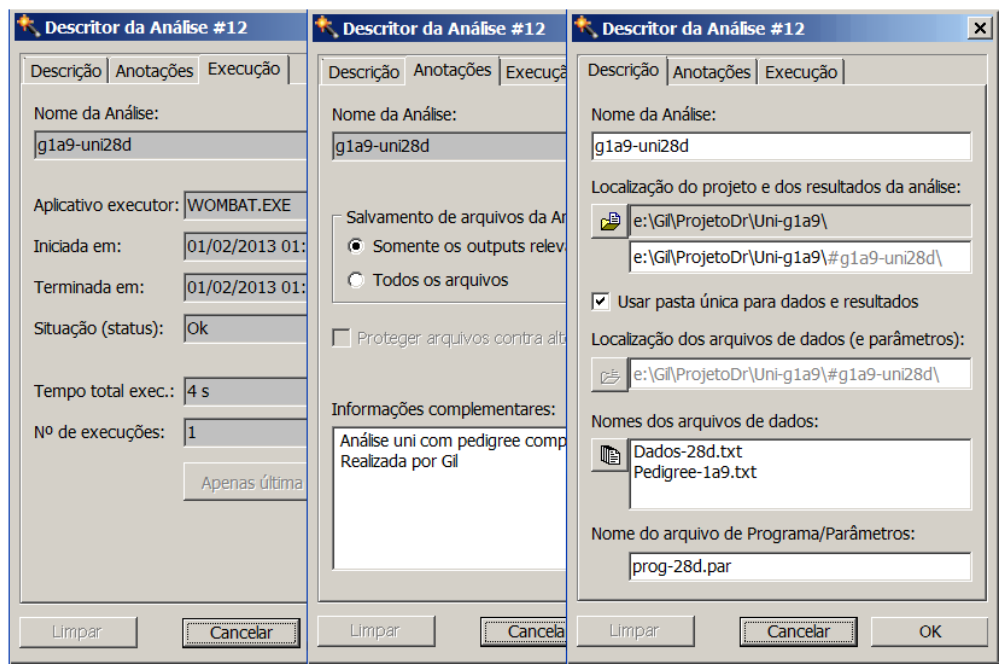


The Guaiaca documentation includes examples of configuration files used to integrate the generic interface with the WOMBAT and INTERGEN applications.

There are two methods for establishing integrated environments of target applications with Guaiaca: isolated or fully integrated environments. For the first, two specific instances of Guaiaca with independent analysis banks are made. The second is based on a single instance of Guaiaca that centralizes the history of all analyses performed in a single database and switches the integrated environments as required. This is the preferred method for similar cases to the experienced, wherein the researcher uses different methods for analysis represented by different applications (WOMBAT and INTERGEN) in the same research context.

Analysis history catalog. The performed analysis descriptors are maintained in a database that represents the Analysis History. From this history, the user can retrieve and easily access previously planned and/or performed analyses and view all their input, output, and parameters files, and then reproduce the interface state to correspond to the task act. In order to open a cataloged analysis, it is possible to browse the selection list. While browsing the list, it is also possible to receive a hint (pop-up description) with a brief explanation of each descriptor without opening the analysis. For each tool installation, a single history file is created - Guaiaca-Hist.dat file - regardless of the number of linked target applications (Figure 1B). The target application used for an analysis is identified in the corresponding descriptor. The history access for browsing and selecting a cataloged analysis is performed via a specific control of the interface in the main window, as shown in Figure 2B.

Any data analysis in this context starts with the creation of a descriptor, even if its result is later discarded (not saved). Initially, the user provides the preparation informations for analysis. Insofar as this is developed, additional informations are automatically added to the descriptor. It is also possible to add analyst comments or remarks on the conditions and/or analysis results for registration and further discussion or appreciation.

Visualization of an analysis descriptor in the corresponding window is activated from controls available in the main window interface. Its visual composition (Figure 2C) distributes the attributes into three groups: description, notes, and execution.

The descriptor data structure consists of the following attributes:

a) Information provided or confirmed by the researcher: name given to the analysis (unique ID); list with data files names; name of the parameter (program) file; operating mode indicators (parameters file protected from change, single folder for data and results, saving all resulting files or only those relevant); project folder name (the folder where the analysis is included); data file location folder name (if the single folder indicator is off); and observations and comments that can include the analyst's identification;

b) Information generated and updated by the tool: analysis order number in history; target application name; run options for the target application (command-line options); analysis execution summary (number of additive executions, timestamps of start and end of the last additive execution, total accumulated time, and status of the last run).

Tests. A set of quail data concerning the pedigree information and body weight evaluations, that consists of 5726 records composed of 19 fields, was used for the tests. The Data Assistant functions were used to transform the collected data structure, from the conventional form of a single record of information on each individual (database) to an extracted form of text files with the necessary and prepared data for analysis through the WOMBAT (MEYER, 2007, 2014) and INTERGEN (CARDOSO, 2008) applications. 
Several single and multi-trait analyses were performed with quail data and configured target applications through use of the Execution Assistant interface. These analyses were cataloged and then revisited with the help of the interface for finding, viewing, and rerunning with changes in parameters or data. The tests show that: (a) the analysis results and the time required to obtain such results suffer no interference from interface processing; (b) the interface provides a greater degree of usability of the target application, thus easing use by the researcher to manage and utilize its input and output structures immediately and simultaneously. Some of the information about one of these examples are highlighted in Figure 2.

Current Stage and Availability. The Guaiaca tool was modeled as a "utility belt" for the researcher to manipulate and analyze data. It features a generic and configurable GUI for each specific data analysis application, according to user preferences. The 1.0 Beta version of this application is now available free of charge to the scientific community and developers who want to experiment or add their generic interface with other scientific applications. The Beta version can be downloaded from the Guaiaca website (http:// wp.ufpel.edu.br/gilmedeiros/guaiaca). At this stage, the package includes the programs, documentation, sample of configuration files for combined use with tested target applications, and the installer program of software engine that implements access to the database environment. Desired target applications must be obtained from their official websites or other means. The documentation included in the package provides guidance for obtaining the target applications used for combined tests with the generic interface.

Guaiaca can also be useful as a complementary tool for applications that have their own GUI. In this case, its functionality can be used without any connection to a target application.

To install the software, the user simply unpacks the downloaded file and follows the directions that accompany the package. The required tasks are to create the indicated folders on the user's work environment, copy the files obtained for these folders, and install the database engine resource.

In this initial version, exclusively for the Windows operating system, Guaiaca has been released in the form of two executable modules produced for the 32-bit architecture. These modules correspond to the Data Assistant and Execution Assistant, which can constitute distinct operating environments, if desired, or a single integrated environment. Implementation of most Data Assistant functions is dependent on the installation of the access mechanism to the database environment. The Execution Assistant interface activates the target application by creating a separate process in the operating system.

Two types of documents are available for user guidance: the Guaiaca User Manual in PDF format, and guidance documents for customizing the generic interface. Customization refers to the link between the interface and target application and preparation of the Code and Options Guides. These documents are accessible directly from the Help menu of the Guaiaca GUI.

The target application's manual, if available, can also be accessed from the Guaiaca Help menu, since this is configured in the connection setup of the Execution Assistant with the target application. It is also possible to select and connect to the GUI some consolidated example of the target application use. This facilitates exploratory demonstration of the interface features and the benefits to view, understand, and explore the methods, techniques, and models implemented by the target application.

\section{Features to be incorporated in the future.} Guaiaca development is still ongoing to consolidate the functional components already defined and include several tools or additional features. Among them, the following are prominent: automatic data capture from electronic devices (scales, for example); transformations on data in order to generate new 
structures and/or variables; installation of alternative languages; alternative and equivalent encoding for commands/codes (synonyms in abbreviated form or in other languages); import and implicit treatment of other data storage formats (currently, only the database format is managed directly, and conversion to/from text is made explicitly via the Manipulations/Rearrange function); graphics generation; expansion of the generic interface with wizards for specific target applications aimed at the automatic generation of parameter files (programs); inclusion of new supplementary information in the analysis descriptor; detailed criteria to search cataloged analyses; and auxiliary functions commonly used in the analysis of data on the genetic improvement of animals, such as the calculation of inbreeding coefficients in populations under selection.

\section{References}

BOLDMAN, K. G.; KRIESE, L. A.; Van VLECK, L. D.; Van TASSEL, C. P.; KACHMAN, S. D. A manual for use of MTDFREML. A set of programs to obtain estimates of variance and covariance. Lincoln: USDA/ARS, 1995. $120 \mathrm{p}$.

CARDOSO, F. F. Manual de utilização do programa INTERGEN - Versão 1.0 em estudos de genética quantitativa animal. Bagé: Embrapa Pecuária Sul, 2008. 74 p. (Documentos, 74).

CRUZ, C. D. GENES - a software package for analysis in experimental statistics and quantitative genetics. Acta Scientiarum. Agronomy, Maringá, v. 35, n. 3, p. 271-276, 2013.

DELWICHE, L. D.; SLAUGHTER, S. J. The little SAS book: a primer. $5^{\text {th }}$ ed. Cary, NC: SAS Institute Inc, 2012. $376 \mathrm{p}$.

DIONELLO, N. J. L.; CORREA, G. S. S.; SILVA, M. A.; CORRÊA, A. B.; SANTOS, G. C. Estimativas da trajetória genética do crescimento de codornas de corte utilizando modelos de regressão aleatória. Arquivo Brasileiro de Medicina Veterinária e Zootecnia, Belo Horizonte, v. 60, n. 2, p. 454-460, 2008.

FERREIRA, D. F. Estatística computacional em Java. Lavras: Ed. UFLA, 2013. v. 1, 695 p.
GARRICK, D. J.; SAATCHI, M. Opportunities and challenges for genomic selection of beef cattle. Revista Brasileira de Zootecnia, Viçosa, MG, v. 40, p. 310-316, 2011. Suplemento Especial.

GILMOUR, A. R.; GOGEL, B. J.; CULliS, B. R.; THOMPSON, R. ASReml User Guide Release 3.0. VSN International Ltd. Hemel Hempstead: HP1 1ES, UK, 2009.398 p. Available at: <http://www.vsni.co.uk $>$. Accessed at: 24 nov. 2014.

LEGARRA, A.; AGUILAR, I.; MISZTAL, I. A relationship matrix including full pedigree and genomic information. Journal of Dairy Science, Champaign, v. 92, n. 9, p. 4656-4663, 2009.

MADAN, A.; DUBEY, S. K. Usability evaluation methods: a literature review. International Journal of Engineering Science and Technology, Singapore, v. 4, n. 2, p. 590-599, 2012.

MEYER, K. WOMBAT - a program for mixed model analyses by restricted maximum likelihood. User Notes. Armidale: Animal Genetics and Breeding Unit, University of New England, 2014. 107 p. Available at: $<$ http://didgeridoo.une.edu.au/ $/ \mathrm{km} /$ download. php?file=WombatManual.pdf $>$. Acessed at: 18 mar. 2015.

WOMBAT - a tool for mixed model analyses in quantitative genetics by restricted maximum likelihood (REML). Journal of Zhejiang University SCIENCE B, Hangzhou, v. 8, n. 11, p. 815-821, 2007.

DFREML - a set programs to estimate variance components under an individual animal model. Journal of Dairy Science, Champaign, v. 71, p. 33-34, 1988. Supplement 2.

MISZTAL, I.; TSURUTA, S.; LOURENÇO, D.; AGUILAR, I.; LEGARRA, A.; VITEZICA, Z. Manual for BLUPF90 family of programs. Athens, USA: University of Georgia, 2014. 125 p. Available at: $<$ http:// nce.ads.uga.edu/wiki/doku.php>. Acessed at: 24 nov. 2014.

RESENDE, M. D. V. Selegen-Reml/Blup: sistema estatístico e seleção genética computadorizada via modelos lineares mistos. Colombo: Embrapa Florestas, 2007. 360 p.

STATISTICAL ANALYSIS SYSTEM INSTITUTE - SAS INSTITUTE INC. SAS 9.3 Companion for Windows. Cary, NC: SAS Institute Inc, 2010. 
